\title{
MRI of the wrist in early rheumatoid arthritis
}

\section{G Peterfy}

\section{Can it be used to predict long term functional outcome?}

$\mathrm{T}$ he past several years have witnessed unprecedented advances in rheumatology, with the introduction of several new compounds capable of halting the relentless progression of joint destruction and functional disability in patients with rheumatoid arthritis (RA). With these successes, however, have come new pressures for medical imaging to resolve even the slightest traces of erosive joint damage and to identify pre-erosive inflammatory features that can accurately predict which patients will go on to severe functional debility if they do not receive aggressive structure modifying treatment immediately.

\section{PREVIOUS DEMAND FOR IMAGING JOINT STRUCTURE}

Before the introduction of effective treatment, rheumatology's demand for imaging joint structure was modest, at best (fig 1). Although it was widely accepted that joint damage was a key driver of functional disability in RA, particularly in late disease, ${ }^{1-3}$ without effective treatments to prevent erosive destruction, there was limited need for detailed information about the integrity of joint structure. Magnetic resonance imaging (MRI) promised to tell more about bone erosion, synovitis, and the integrity of cartilage, ligaments and other articular tissues than radiography ever could, but the additional cost and inconveniences associated with MRI were not felt to be worth the extra performance. The information simply did not impact on clinical management. Accordingly, most rheumatologists focused primarily on clinical and laboratory features of the disease, and used imaging only sparingly-if at all. Not surprisingly, the development of MRI for this purpose languished. However, the recent introduction of effective structure modifying treatments has changed the way that rheumatologists manage patients with RA, and this has created new demands on imaging both in clinical practice and in clinical research

\section{MONITORING TRIALS: MORE SENSITIVE METHODS NEEDED}

One important change is that it is no longer ethical to withhold effective treatment from patients, and therefore to conduct placebo controlled clinical trials. This means that putative new agents must be tested against established treatments with known efficacy. Because such studies show much slower progression and smaller differences among treatment groups, they take substantially longer and require greater numbers of patients and clinical sites to achieve statistical significance. This increases the cost of clinical research and slows progress considerably. Unless more sensitive methods of predicting and monitoring treatment effect are developed the financial and practical ramifications of this problem will severely hinder further progress in therapeutic agents for RA.

\section{"Sensitive methods of monitoring treat- ment effects are needed urgently"}

\section{TARGETING EARLY DISEASE}

Additionally, the availability of effective structure modifying treatment has stimulated a trend towards early, aggressive treatment before the development of joint damage $e^{4}$ and associated irreversible functional disability. ${ }^{6-8}$ During the first few years of disease, inflammation rather than structural damage accounts for most functional disability in RA. ${ }^{19}$ By eliminating inflammation at this stage, therefore, one can achieve full functional recovery. Indeed, inflammation is potentially reversible at any stage of the disease. However, as structural damage accumulates an increasing proportion of functional disability becomes irreversible. Accordingly, current treatment strategies target early disease to limit cumulative structural damage. ${ }^{5}$

However, $30 \%-40 \%$ of cohorts with early RA do not progress, and therefore may not require aggressive treatment. Some have advocated treating all patients aggressively anyway in order to avoid missing those who might progress. ${ }^{10}$ However, such a catch-all strategy carries significant financial and toxicity implications, as well as potential production challenges in some cases. Moreover, including non-progressors in clinical trials dilutes statistical power and necessitates exposing larger numbers of patients to experimental treatments for longer periods of time in order to test therapeutic efficacy adequately. Clearly, there is a need for better ways of identifying the aggressive phenotype of RA in early disease.

DETECTION OF EROSIVE DAMAGE Absence of erosive damage on radiographs accurately identifies nonprogressors among patients with established disease (>18 months), but is only $41 \%$ accurate in patients with RA of less than 6 months' duration. ${ }^{10}$ Devauchelle Pensec et al found that radiographs acquired before 1 year of disease could not even reliably predict which patients would still have the diagnosis of RA 2 years later. ${ }^{11}$ Positive radiographs in their study were highly specific $(96 \%)$ but diagnostically insensitive $(17 \%)$. Others have reported similar findings. ${ }^{12-14}$ Earlier reports by McQueen ${ }^{15}{ }^{16}$ of the same cohort of patients described in Benton's article in this issue of the Annals ${ }^{70}$ asserted that fewer than $20 \%$ of patients with RA of less than 6 months' duration show erosions on radiographs. In a different study by Machold et al fewer than 13\% of patients with RA showed radiographic erosions before 3 months. ${ }^{17}$ Accordingly, technical sensitivity for bone erosion is a critical performance requirement for imaging in early RA.

"Unlike MRI, radiography cannot detect all erosions or pre-erosive inflammation"

Unfortunately, radiography's capacity for increased sensitivity is limited. Erosions that are not aligned tangentially to the $x$ ray beam (typically, erosions of dorsal and volar bone surfaces) are projected en face and can be obscured by superimposed bone. Penetrating erosions that are predominantly intramedullary and therefore surrounded by bone are also often obscured and difficult, if not impossible, to see. Additionally, joint flexion/contracture, subluxation or changes in $x$ ray beam centring can simulate joint space narrowing on radiographs. Radiography also cannot detect pre-erosive inflammation or directly visualise non-osseous components of the joint, such as articular cartilage, synovium, joint effusion, ligaments, tendons, discs, labra, menisci, or muscles. 


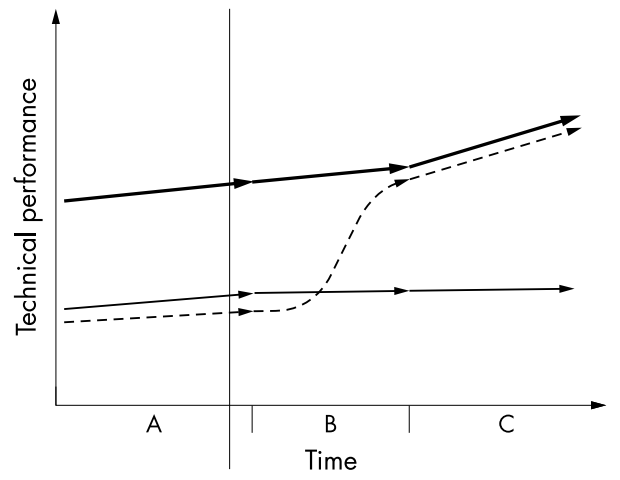

Figure 1 Technical demand-performance relationships for radiography and MRI in RA. (A) Before the availability of effective structure modifying treatment, clinical rheumatology's demand for technical performance in imaging (broken line) was modest and flat, increasing only slightly over time. Radiography (thin line) met these technical demands, and was the dominant imaging method used. MRI (thick line) was technically better than radiography, but rheumatologists were satisfied with radiography's performance, and therefore not willing to pay more for MRI. MRI exhibited a performance surplus, and was not used. (B) With the introduction of effective treatments for RA, rheumatology's technical requirements for imaging have increased beyond the delivery ability of radiography, creating a new demand for MRI's added performance. (C) Rheumatology's technical demands for imaging will continue to increase over time, and this will drive further technical development in MRI to keep pace.

MRI, on the other hand, is unparalleled in its ability to image arthritic joints. Because it generates tomographic rather than projectional images, MRI can delineate erosions along all surfaces of bones, including the dorsal and volar surfaces, as well as the intramedullary component of penetrating erosions (fig 2). Dozens of studies have shown that MRI is several times more sensitive than radiography ${ }^{16}{ }^{18-27}$ or ultrasound ${ }^{27}$ for detecting bone erosions. This advantage of MRI has been demonstrated not only with conventional $1.5 \mathrm{~T}$ MRI but also with small, low field (0.2 T) MRI systems, ${ }^{27}{ }^{28}$ which can image joints at a fraction of the cost of conventional MRI. ${ }^{29}$

Baseline MRI showed bone erosions in $42 \%$ of the patients with early RA in Benton's study, ${ }^{70}$ whereas radiography detected erosions in only 15\% of these patients. Within 1 year, MRI was able to show the emergence of 134 new erosions. Moreover, the baseline erosion score was predictive of radiographic erosion score at 2 years $(p=0.004) .{ }^{16}$ Sixty one per cent of patients with erosions on MRI at baseline showed erosions on radiographs after 2 years, whereas only $18 \%$ of patients without baseline MRI erosions showed radiographic erosions in the same time interval. When bone marrow oedema, synovitis, and tendonitis/tenosynovitis were also taken into account, MRI was even more predictive of subsequent radiographic erosion, offering optimised sensitivity and specificity values of $80 \%$ and $76 \%$, respectively, and a negative predictive value of $86 \% .{ }^{16}$ Accordingly, in contrast with radiography, MRI can identify patients with early RA who are unlikely to express an aggressively erosive phenotype and therefore less in need of aggressive, costly, structure modifying treatment. Excluding these people from clinical trials of putative new treatments can reduce the number of patients, study sites, and study duration required to test treatment efficacy.

\section{BONE MARROW OEDEMA}

One of the most intriguing MRI features of active RA is what many have called bone marrow oedema. This feature presents as free water signal in otherwise fatty marrow of articular bones, and is most conspicuous on fat suppressed, $\mathrm{T}_{2}$ weighted images (fig 3 ). In contrast with bone erosions, which have sharply defined margins and contain only synovial fluid or synovial tissue, areas of marrow oedema typically have poorly defined, feathery margins and contain residual trabeculae and marrow tissue, which are identified by the presence of magnetic susceptibility effects and $T_{1}$ contrast, respectively. Additionally, these areas are enhanced after intravenous injection of contrast material containing gadolinium (Gd) (fig 3), ${ }^{30}$ and correlate with clinical markers of inflammation, including $\mathrm{C}$ reactive protein (CRP) and disease activity score (DAS). ${ }^{70}$ Accordingly, "osteitis" may be a more appropriate term for this inflammatory feature. ${ }^{30}$

\section{OSTEITIS}

Several investigators have reported a high prevalence of osteitis in the hands and wrists of patients with RA, and presented evidence that osteitis can progress to bone erosions. ${ }^{15} 192431-33$ In the study by Benton et al, osteitis at baseline in patients with early RA was more predictive of bone erosions and functional outcome 6 years later than were any other MRI features, clinical features, or CRP, alone or in combination. ${ }^{70}$ Consistent with previous studies, erosive damage correlated with functional disability at 6 years but not in early disease, whereas osteitis correlated with disability in early disease, but not at 6 years. Interestingly, although DAS and the Health Assessment Questionnaire (HAQ) improved mildly during the first 2 years of the study, presumably due to treatment (no TNF $\alpha$ inhibitors or other biological agents), the median osteitis score remained relatively constant throughout the 6 years, and the bone erosion score increased relentlessly and almost linearly over that same period.

Examples of osteitis resolving before the development of frank erosion have also been reported in this group and others. ${ }^{15}{ }^{33}$ Accordingly, osteitis may be useful not only for predicting which patients are likely to progress but also for monitoring anti-erosive treatment in these patients. In contrast with bone erosion, which is typically used as a negative marker, in that it indicates efficacy by not happening, ${ }^{34}$ recession of pre-existing osteitis provides direct evidence that the process driving erosion has ceased, and thus offers more rapid indication of therapeutic effect. Such a responsive marker would be useful for optimising treatment in clinical practice, and for short proof-of-concept trials and other internal decision making studies in clinical research.

\section{"HEALING" OF EROSIONS}

Filling in, or "healing", of pre-existing erosions, a phenomenon which has been seen both with radiography ${ }^{35}$ and MRI (fig 2), similarly provides direct indication that the erosive process has stopped., and thus may also allow more rapid assessment of therapeutic efficacy. How frequently erosion "healing" occurs and whether or not it is accompanied by functional improvement is not known. It appears to be relatively uncommon on radiographs, ${ }^{35}$ but it is not an infrequent finding on MRI, at least anecdotally. The reason for this discrepancy may be technical. As for other osseous lesions, most radiographic lucency associated with RA erosions is attributable to cortical bone loss. The intramedullary component of bone erosions (fig 2), unless associated with a calcified rim, is difficult to see with radiography. Penetrating erosions that have only small cortical components, therefore, are underestimated or occult on radiographs, particularly if the cortical defect is projected en face. These types of erosions, however, may be predisposed to reparative filling in, as they are surrounded by bone on 

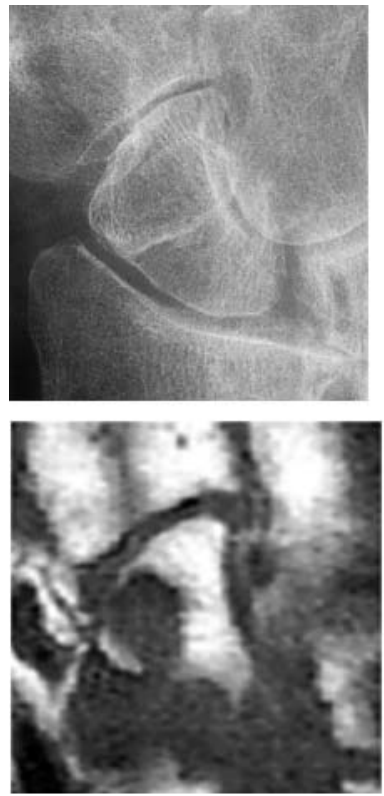

A
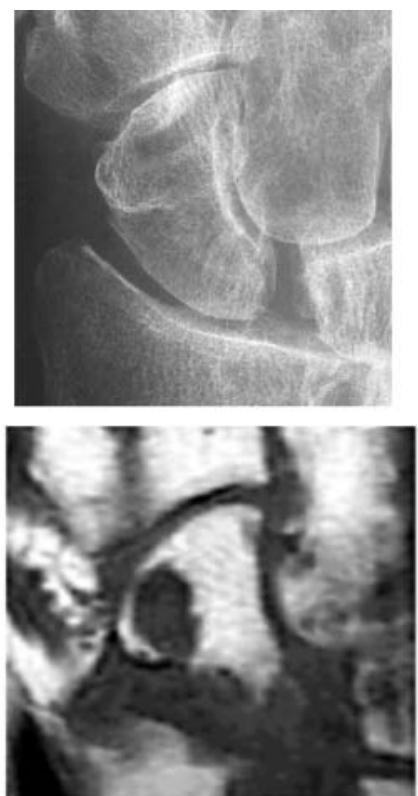

B
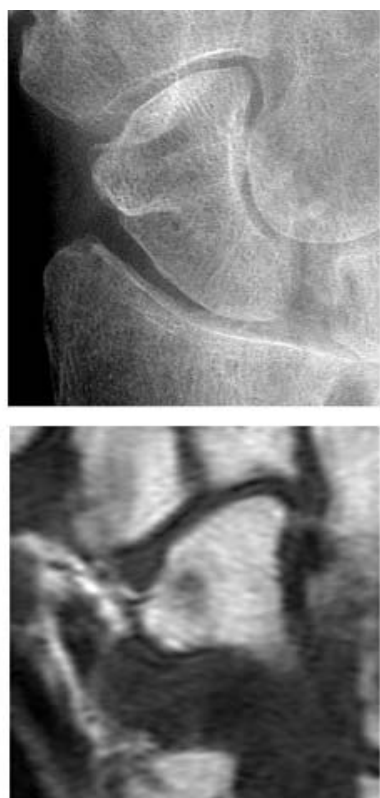

C
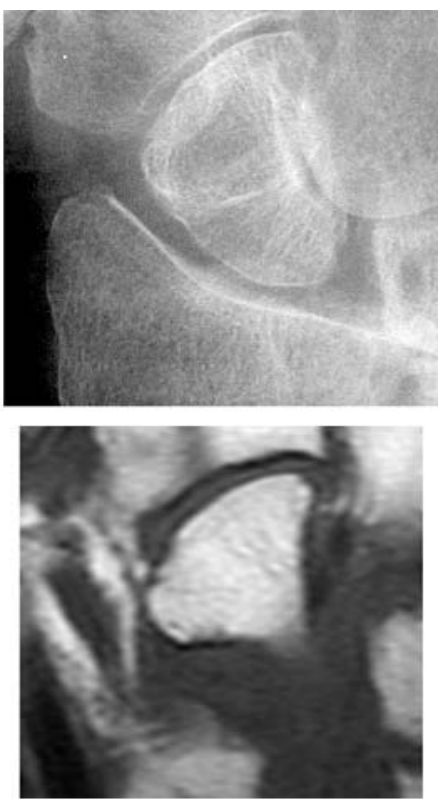

D

Figure $2 M R I$ is more sensitive than radiography for bone erosions. Radiographs and coronal $T_{1}$ weighted images at baseline (A); 3 months $(B)$; 6 months (C); and 24 months (D) of a patient treated with methotrexate show a penetrating bone erosion in the distal pole of the scaphoid bone with a large intramedullary component. Despite the size of this erosion, it is barely visible with radiography. Follow up images show gradual filling in of the erosion over 2 years. Reproduced with permission of the copyright holder from Peterfy CG. Magnetic resonance imaging of the wrist in rheumatoid arthritis. Semin Musculoskelet Radiol 2001;5:275-88.

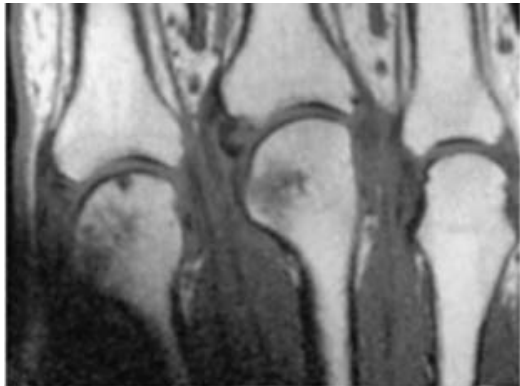

A

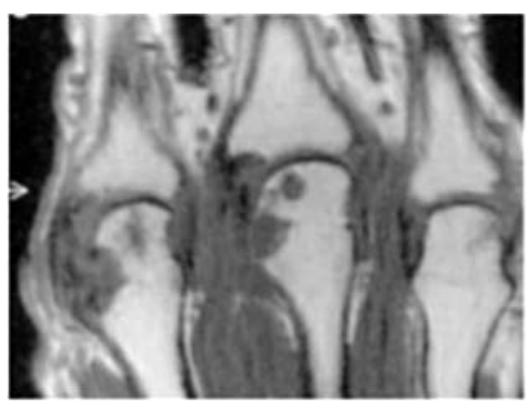

D

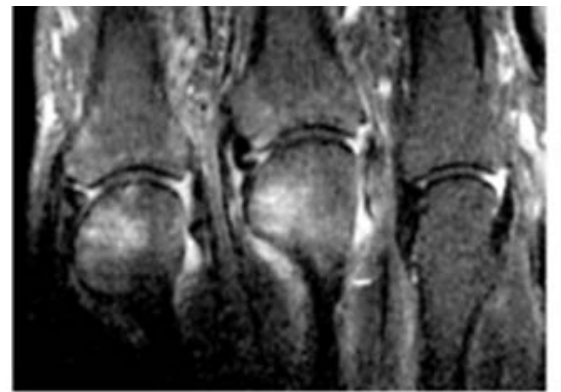

B

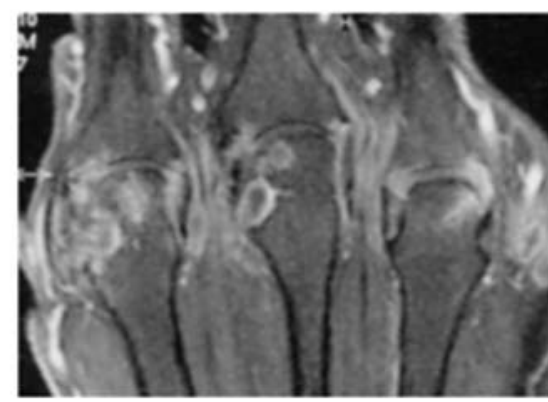

E

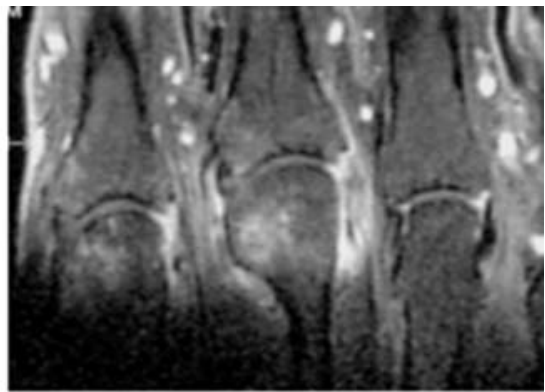

C

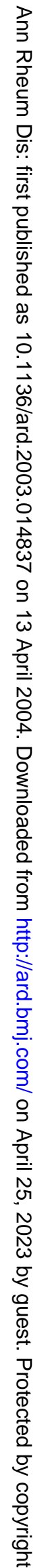

Figure 3 Pre-erosive osteitis. Coronal $T_{1}$ weighted $(A)$ and fat suppressed $T_{2}$ weighted $(B)$ spin echo images of the metacarpophalangeal joints of a patient with RA show areas of osteitis in the distal second and third metacarpals. The more sensitive fat suppressed $T_{2}$ weighted images also show these changes in the adjacent proximal phalanges. Fat suppressed $T_{1}$ weighted spin echo with Gd-DTPA (C) shows enhancement of these areas consistent with inflammation. Follow up images 17 months later ( $T_{1}$ weighted images without (D) and with (E) fat suppression and Gd-DTPA) show development of bone erosions with sharply defined rim enhancing margins at these sites of previous osteitis, and a new focus of osteitis in the previously quiescent fourth metacarpal head. Reproduced with permission of the copyright holder from Peterfy CG. Magnetic resonance imaging of the wrist in rheumatoid arthritis. Semin Musculoskelet Radiol 2001;5:275-88. 
all sides. Non-penetrating erosions associated with extensive cortical bone loss may lack sufficient scaffolding to guide bone synthesis. Because MRI is disproportionately more sensitive to penetrating erosions, MRI would be expected to detect more "healing" erosions than radiography does. Again, erosion "healing" does not necessarily imply biomechanical recovery. However, it is a direct indication that the erosive process has stopped, and therefore it is a potentially useful marker of therapeutic efficacy. However, no reported studies have systematically examined erosion "healing" on MRI thus far.

\section{SYNOVITIS}

Synovitis is another hallmark feature of RA that is visible with MRI. In the absence of fatty infiltration (lipoma arborescens ), ${ }^{36}$ fibrosis, or iron accumulation (haemosiderosis), however, thickened synovial tissue can be difficult to differentiate from adjacent synovial fluid with conventional MRI pulse sequences, ${ }^{37}$ and intravenous contrast material containing $\mathrm{Gd}$ is typically required..$^{21}$ 37-44 Various segmentation techniques can be used to measure the volume of this enhancing, inflammatory compartment in the wrist or fingers. ${ }^{45} 46$ In a recent study Savnik et al measured similar synovial volumes with low field $(0.2 \mathrm{~T})$ dedicated extremity MRI as with conventional 1.5 T MRI. ${ }^{47}$ A number of studies have found that synovial volume correlates with joint swelling and tenderness, ${ }^{21} 45464849$ and is predictive of bone erosion on follow up images. ${ }^{15} 21283350$ In one of these studies clinical examination detected only $49 \%$ of cases of synovitis demonstrable with low field dedicated extremity MRI. ${ }^{28}$ In the study by Benton et al the synovitis score did not correlate with clinical features at any time point, but it did predict erosions on MRI at 6 years. ${ }^{70}$

In addition to volume, the rate and magnitude of synovial enhancement on sequential MR images after bolus intravenous injection of contrast material containing Gd has been shown to correlate with the histological severity of inflammation in the synovium ${ }^{51-53}$ and with clinical markers of disease activity. ${ }^{50}$ Enhancement of synovium can be accurately quantified by dynamic MRI of single sections through the wrist. ${ }^{54}$ In a recent randomised clinical trial, the knees of 34 patients with RA were examined with dynamic, gadolinium enhanced MRI at baseline and after 4 months of treatment with leflunomide ${ }^{17}$ or methotrexate. ${ }^{17}{ }^{55}$ Despite the small number of patients and short study duration, measurements of the rate of synovial enhancement showed a statistically significant difference between the two treatment groups, whereas the clinical examinations could not. In an earlier report, histological findings from synovial biopsies of the same joints correlated well with these MRI results.56 Several other studies have also shown that synovial volume and synovial enhancement decrease with treatment, but the follow up interval in many of these was 6 months or longer. ${ }^{21} 4950$ 57-60

\section{ARTICULAR CARTILAGE}

Another unique strength of MRI is its ability to directly visualise articular cartilage. ${ }^{61-64}$ Direct imaging of this tissue is more specific than radiographic joint space width, and tomography provides greater anatomical coverage of the joint surface than projection does. A number of morphological and compositional MRI markers of cartilage integrity have been developed, ${ }^{6165-67}$ but most of this work derives from the knee, because the articular cartilage in the hand and wrist is extremely thin, and high resolution imaging techniques are required.

\section{TENDON PATHOLOGY}

In addition to monitoring changes in the bones, cartilage, and synovium, MRI can directly visualise the full spectrum of tendon pathology, and has been shown to identify tendonitis and tendon rupture with greater accuracy than clinical examination. ${ }^{68}{ }^{69}$ In Benton's study, tendon score was not itself predictive of either bone erosion or functional disability, but when combined with bone erosion, osteitis, and synovitis both were predictable. ${ }^{70}$ Ligaments and the triangular fibrocartilage complex can also be examined directly with MRI. However, to date, very little attention has been given to imaging these structures in RA.

\section{SUMMARY}

In summary, as effective structure modifying treatments for RA begin to enter mainstream clinical practice, and early aggressive treatment becomes more widespread, the use of conventional radiography for managing patients with RA will continue to diminish. As Benton's report demonstrates, MRI offers a powerful alternative to radiography in this circumstance. It is far more sensitive than radiography for bone erosion in patients with early RA, and can detect pre-erosive features, such as osteitis and synovitis, along with tendonitis and potentially other MRI features that can be used to predict which patients will go on to severe destructive joint damage and irreversible functional disability. Being able to predict this accurately at the time of initial presentation is crucial to effective patient management.
Ann Rheum Dis 2004;63:473-477. doi: 10.1136/ard.2003.014837

Correspondence to: $\operatorname{Dr}$ C G Peterfy, Synarc Inc, 575 Market Street, 17th Floor, San Francisco 94105, CA, USA; charles.peterfy@synarc.com

\section{REFERENCES}

1 Welsing PM, van Gestel AM, Swinkels HL, Kiemeney LA, van Riel PL. The relationship between disease activity, joint destruction, and functional capacity over the course of rheumatoid arthritis. Arthritis Rheum 2001;44:2009-17.

2 Scott DL, Pugner K, Kaarela K, Doyle DV, Woolf A, Holmes J, et al. The links between joint damage and disability in rheumatoid arthritis. Rheumatology (Oxford) 2000;39:122-32.

3 Clarke AE, St-Pierre Y, Joseph L, Penrod J, Sibley JT, Haga M, et al. Radiographic damage in rheumatoid arthritis correlates with functional disability but not direct medical costs. J Rheumatol 2001;28:2416-24.

4 Irvine S, Munro R, Porter D. Early referral, diagnosis, and treatment of rheumatoid arthritis: evidence for changing medical practice. Ann Rheum Dis 1999;58:510-13.

5 Emery P. Evidence supporting the benefit of early intervention in rheumatoid arthritis. J Rheumatol 2002;29(suppl 66):3-6.

6 Landewe RB, van den Borne BE, Houkes I, Schild F, van der Heyden PC, Hazes JM, et al. The benefits of early treatment in rheumatoid arthritis: confounding by indication, and the issue of timing no increased risk of malignancies and mortality in cyclosporin A-treated patients with rheumatoid arthritis. Arthritis Rheum 2003;48:1-5.

7 Bukhari MA, Wiles NJ, Lunt M, Harrison BJ, Scott DG, Symmons DP, et al. Influence of disease-modifying therapy on radiographic outcome in inflammatory polyarthritis at five years: results from a large observational inception study. Arthritis Rheum 2003;48:46-53.

8 Emery P, Breedveld FC, Dougados M, Kalden JR, Schiff MH, Smolen JS. Early referral recommendation for newly diagnosed rheumatoid arthritis: evidence based development of a clinical guide. Ann Rheum Dis 2002;61:290-7.

9 van der Heijde D. Radiographic progression in rheumatoid arthritis: does it reflect outcome? Does it reflect treatment? Ann Rheum Dis 2001:60(suppl 3):iii47-50.

10 Paulus HE, Oh M, Sharp JT, Gold RH, Wong WK Park GS, et al. Correlation of single time-point damage scores with observed progression of radiographic damage during the first 6 years of rheumatoid arthritis. J Rheumatol 2003;30:705-13

11 Devauchelle Pensec V, Saraux A, Berthelot JM, Alapetite S, Chales G, Le Henaff C, et al. Ability of hand radiographs to predict a further diagnosis of rheumatoid arthritis in patients with early arthritis. J Rheumatol 2001 ;28:2603-7.

12 Mau W, Raspe HH, Mersjann H. Early arthritides: nosography, nosology, and diagnostic criteria. Scand J Rheumatol Suppl 1989;79:3-12.

13 Nissila M, Isomaki $H$, Kaarela K, Kiviniemi $P$, Martio J, Sarna S. Prognosis of inflammatory joint diseases. A three-year follow-up study. Scand J Rheumatol 1983;12:33-8.

14 van der Horst-Bruinsma IE, Speyer I, Visser H, Breedveld FC, Hazes JM. Diagnosis and course of early-onset arthritis: results of a special early arthritis clinic compared to routine patient care. Br J Rheumatol 1998;37:1084-8.

15 McQueen F, Stewart N, Crabbe J, Robinson E, Yeoman S, Tan $\mathrm{P}$, et al. Magnetic resonance imaging of the wrist in early rheumatoid arthritis reveals progression of erosions despite clinical improvement. Ann Rheum Dis 1999;58:156-63.

16 McQueen FM, Benton N, Crabbe J, Robinson E, Yeoman S, McLean L, et al. What is the fate of erosions in early rheumatoid arthritis? Tracking individual lesions using $x$-rays and magnetic resonance imaging over the first two years of disease. Ann Rheum Dis 2001;60:859-68.

17 Machold KP, Stamm TA, Eberl GJM, Nell VKP, Dunky A, Uffmann $M$, et al. Very recent onset arthritis-clinical, laboratory, and radiological 
findings during the first year of disease. $J$ Rheumatol 2002;29:2278-87.

18 Jorgensen C, Cyteval C, Anaya J, Baron M Lamarque J, Sany J. Sensitivity of magnetic resonance imaging of the wrist in very early rheumatoid arthritis. Clin Exp Rheumatol 1993;11:163-8.

19 McQueen F, Stewart N, Crabbe J, Robinson E, Yeoman $S$, Tan $P$, et al. Magnetic resonance imaging of the wrist in early rheumatoid arthritis reveals a high prevalence of erosions at four months after symptom onset. Ann Rheum Dis 1998:57:350-60.

20 Peterfy C, Dion E, Miaux Y, White D, Jiang $Y$, Lu $Y$, et al. Comparison of MRI and X-ray for monitoring erosive changes in rheumatoid arthritis. Arthritis Rheum 1998:41(suppl):S51 .

21 Østergaard M, Hansen M, Stolenberg M, Gideon P, Klarlund M, Jensen KE, et al. Magnetic resonance imaging-determined synovial membrane volume as a marker of disease activity and a predictor of progressive joint destruction in the wrists of patients with rheumatoid arthritis. Arthritis Rheum 1999;42:918-29.

22 Klarlund $M$, Østergaard $M$, Gideon P, Sorensen K, Hendriksen O, Lorenzen I. Wrist and finger joint $M R$ imaging in rheumatoid arthritis. Acta Radiol 1999;40:400-9

23 Foley-Nolan D, Stack J, Ryan M, Redmond U, Barry C, Ennis J, et al. Magnetic resonance imaging in the assessment of rheumatoid arthritis - a comparison with plain film radiographs. Br J Rheumatol 1991;30:101-6.

24 McGonagle D, Conaghan PG, O'Connor P Gibbon W, Green M, Wakefield R, et al. The relationship between synovitis and bone changes in early untreated rheumatoid arthritis: a controlled magnetic resonance imaging study. Arthritis Rheum 1999:42:1706-11.

25 Østergaard M, Gideon P, Sorenson K, Hansen M Stoltenberg M, Hendriksen O, et al. Scoring of synovial membrane hypertrophy and bone erosions by MR imaging and clinically active and inactive rheumatoid arthritis of the wrist. Scand J Rheumatol 1995:24:212-18.

26 Emery P, Luqmani R. The validity of surrogate markers in rheumatic disease. $\mathrm{Br} J$ Rheumatol 1993;32(suppl 3):3-8.

27 Backhaus M, Burmester GR, Sandrock D, Loreck D, Hess D, Scholz A, et al. Prospective two year follow up study comparing novel and conventional imaging procedures in patients with arthritic finger joints. Ann Rheum Dis 2002;61:895-904.

28 Lindegaard H, Vallø J, Høslev-Petersen K, Junker P, Østergaard M. Low field dedicated magnetic resonance imaging in untreated rheumatoid arthritis of recent onset. Ann Rheum Dis $2001 ; 60: 770-6$

29 Peterfy CG, Roberts T, Genant HK. Dedicated extremity MRI: an emerging technology. In: Kneeland JB, ed. Radiol Clin N Am. Philadelphia: Saunders, 1996: 1-20.

30 Peterfy CG. Magnetic resonance imaging of the wrist in rheumatoid arthritis. Semin Musculoskele Radiol 2001;5:275-88.

31 Lee JK, Yao L, Wirth CR. MR imaging of solitary osteochondroma: report of eight cases. AJR Am J Roentgenol 1987; 149:557-60.

32 McQueen FM. Magnetic resonance imaging in early arthritis: what is its role? Rheumatology (Oxford) 2000;39:700-6.

33 Savnik A, Malmskov H, Thomsen HS, Graff LB, Nielsen H, Danneskiold-Samsoe B, et al. MRI of the wrist and finger joints in inflammatory joint diseases at 1-year interval: MRI features to predic bone erosions. Eur Radiol 2002;12:1203-10.

34 van der Heijde DMFM. How to read radiographs according to the Sharp/van der Heijde method. $J$ Rheumatol 1999:26:743-5.

35 Sharp JT, van Der Heijde D, Boers M, Boonen A, Bruynesteyn K, Emery P, et al. Repair of erosions in rheumatoid arthritis does occur. Results from 2 studies by the OMERACT Subcommittee on Healing of Erosions. J Rheumatol 2003;30:1 102-7.

36 Feller JF, Rishi $M$, Hughes EC. Lipoma arborescens of the knee: MR demonstration. AJR Am J Roentgenol 1994:163:162-4.

37 Peterfy CG, Majumdar S, Lang P, van Dijke CF, Sack K, Genant H. MR imaging of the arthritic knee: improved discrimination of cartilage, synovium and effusion with pulsed saturation transfer and fat-suppressed T1-weighted sequences. Radiology 1994;191:413-19.

38 Smith HJ, Larheim TA, Aspestrand F. Rheumatic and nonrheumatic disease in the temporomandibular joint: gadolinium-enhanced MR imaging. Radiology 1992; 185:229-34.

39 Yamato M, Tamai K, Yamaguchi T, Ohno W. MR of the knee in rheumatoid arthritis: Gd-DTPA perfusion dynamics. J Comput Assist Tomogr 1993;17:781-5.

40 Drapé JL, Thelen P, Gay-Depassier P Silbermann $O$, Benacerraf R. Intraarticular diffusion of Gd-DOTA after intravenous injection in the knee: MR imaging evaluation. Radiology 1993:188:227-34.

41 Winalski CS, Aliabadi P, Wright RJ, Shortkroff S, Sledge CB, Weissman BN. Enhancement of joint fluid with intravenously administered gadopentetate dimeglumine: technique, rationale, and implications. Radiology 1993;187:179-85.

42 Jevtic V, Watt I, Rozman B, Kos-Golja M, Rupenovic $S$, Logar $D$, et al. Precontrast and postcontrast (Gd-DTPA) magnetic resonance imaging of hand joints in patients with rheumatoid arthritis. Clin Radiol 1993;48: 176-81.

43 Jevtic V, Watt I, Rozman B, Kos-Golija M, Demsar $F$, Jarh $O$. Distinctive radiological features of small hand joints in rheumatoid arthritis and seronegative spondyloarthritis demonstrated by contrast-enhanced (Gd-DTPA) magnetic resonance imaging. Skeletal Radiol 1995:24:351-5.

44 Klarlund M, Østergaard M, Rostrup E, Skjodt H Lorenzen I. Dynamic magnetic resonance imaging of the metacarpophalangeal joints in rheumatoid arthritis, early unclassified polyarthritis and healthy controls. Scand I Rheumatol 2000;29:108-15.

45 Østergaard M, Hansen M, Stoltenberg M, Lorenzen I. Quantitative assessment of the synovial membrane in the rheumatoid wrist: an easily obtained MRI score reflects the synovial volume. Br J Rheumatol 1996;35:965-71.

46 Østergaard M, Stoltenberg M, LovgreenNielsen P, Volck B, Jensen C, Lorenzen I. Magnetic resonance imaging-determined synovial membrane and joint effusion volumes in rheumatoid arthritis and osteoarthritis: comparison with the macroscopic and microscopic appearance of the synovium. Arthritis Rheum 1997:40:1856-67.

47 Savnik A, Malmskov H, Thomasen HS, Bretlau T, Graff LB, Nielsen $H$, ef al. MRI of the arthritic small joints: comparison of extremity MRI (0.2 T) vs high-field MRI (1.5 T). Eur Radio 2001;11:1030-8.

48 Palmer WE, Rosenthal DI, Shoenberg OI, Fischman AJ, Simon LS, Rubin RH, et al. Quantification of inflammation in the wrist with gadolinium-enhanced MR imaging and PET with 2-[F-18]-fluoro-2-deoxy-D-glucose. Radiology 1995; 196:645-55.

49 Sugimoto H, Takeda A, Kano S. Assessment of disease activity in rheumatoid arthritis using magnetic resonance imaging: quantification of pannus volume in the hands. $\mathrm{Br} J$ Rheumatol 1998:37:854-61.

50 Huang J, Stewart N, Crabbe J, Robinson E, McLean L, Yeoman S, et al. A 1-year follow-up study of dynamic magnetic resonance imaging in early rheumatoid arthritis reveals synovitis to be increased in shared epitope-positive patients and predictive of erosions at 1 year. Rheumatology (Oxford) 2000;39:407-16

51 Tamai K, Yamato M, Yamaguchi T, Ohno W. Dynamic magnetic resonance imaging for the evaluation of sunovitis in patients with rheumatoid arthritis. Arthritis Rheum 1994;37:1151-7.

52 Stiskal MA, Neuhold A, Szolar DH, Saeed M, Czerny C, Leeb B, et al. Rheumatoid arthritis of the craniocervical region by MR imaging: detection and characterization. AJR Am J Roentgenol 1995;165:585-92.

53 Østergaard M, Stoltenberg M, LovgreenNielsen P, Volck B, Sonne-Holm SIL. Quantification of synovistis by MRI: correlation between dynamic and static gadoliniumenhanced magnetic resonance imaging and microscopic and macroscopic signs of synovial inflammation. Magn Reson Imaging

1998; 16:743-54.

54 Østergaard M. Different approaches to synovial membrane volume determination by magnetic resonance imaging: manual versus automated segmentation. BrJ Rheumatol 1997;36:1 166-77.

55 Reece RJ, Kraan MC, Radjenovic A, Veale DJ, O'Connor PJ, Ridgeway JP, et al. Comparative assessment of leflunomide and methotrexate for the treatment of rheumatoid arthritis, by dynamic enhanced magnetic resonance imaging. Arthritis Rheum 2002;46:366-72.

56 Kraan MC, Reece RJ, Barg EC, Smeets TJM, Farnell J, Rosenburg R, et al. Modulation of inflammation and metalloproteinase expression in synovial tissue by leflunomide and methotrexate in patients with active rheumatoid arthritis: findings in a prospective, randomized, double-blind, paralleldesign clinical trial in thirty nine patients at two centers. Arthritis Rheum 2000;43:1820-30.

57 Østergaard M, Stoltenberg M, Hendricksen O Lorenzen I. Quantitative assessment of synovial inflammation by dynamic gadolinium-enhanced magnetic resonance imaging. A study of the effect of intra-articular methyl-prednisolone on the rate of early synovial enhancement. $\mathrm{Br} J$ Rheumatol 1996;35:50-9.

58 Kalden-Nemeth D, Grebmeier J, Antoni C, Manger B, Wolf $F$, Kalden J. NMR monitoring of rheumatoid arthritis patients receiving anti-TNFalpha monoclonal antibody therapy. Rheumatol Int 1997; 16:249-55.

59 Lee J, Lee S, Suh J, Yoon M, Song J, Lee C. Magnetic resonance imaging of the wrist in defining remission of rheumatoid arthritis. $J$ Rheumatol 1997;24:1303-8.

60 Huh YM, Suh JS, Jeong EK, Lee SK, Lee JS, Choi BW, et al. Role of the inflamed synovial volume of the wrist in defining remission of rheumatoid arthritis with gadolinium-enhanced 3D-SPGR MR imaging. J Magn Reson Imaging 1999;10:202-8.

61 Peterfy CG. Scratching the surface: articular cartilage disorders in the knee. MRI Clin N Am 2000;8:409-29.

62 Disler D. Fat-suppressed three-dimensional spoiled gradient-recalled MR imaging: assessment of articular and physeal hyaline cartilage. AJR Am J Roentgenol 1997; 169:1117-23.

63 Recht MP, Pirraino DW, Paletta GA, Schils JP, Belhobek GH. Accuracy of fat-suppressed threedimensionl spoiled gradient-echo FLASH MR imaging in the detection of patellofemoral articular cartilage abnormalities. Radiology 1996:198:209-12.

64 Bredella $M$, Tirman P, Peterfy C, Zarlingo M Feller J, Bost $F$, et al. Accuracy of T2-weighted fast spin-echo MR imaging with fat saturation in detecting cartilage defects in the knee: comparison with arthroscopy in 130 patients. AJR Am J Roentgenol 1999;172:1073-80.

65 Peterfy CG, van Dijke CF, Janzen DL, Glüer C Namba R, Majumdar S, et al. Quantification of articular cartilage in the knee by pulsed saturation transfer and fat-suppressed MRI: optimization and validation. Radiology 1994;192:485-91.

66 Bashir A, Gray ML, Hartke J, Burstein D. Nondestructive imaging of human cartilage glycosaminoglycan concentration by MRI. Magn Reson Med 1999:41:857-65.

67 Burstein D, Gray ML, Hartman AL, Gipe R, Foy $B D$. Diffusion of small solutes in cartilage as measured by nuclear magnetic resonance (NMR) spectroscopy and imaging. J Orthop Res 1993;11:465-78

68 Rubens DJ, Blebea JS, Totterman SM, Hooper MM. Rheumatoid arthritis: evaluation of wrist extensor tendons with clinical examination versus MR imaging-a preliminary report. Radiology 1993;187:831-8.

69 Valeri G, Ferrara C, Ercolani P, de Nigris E, Giovagnoni A. Tendon involvement in rheumatoid arthritis of the wrist: MRI findings. Skeletal Radiol 2001;30:138-43.

70 Benton N, Stewart N, Crabbe J, Robinson E, Yeoman S, McQueen FM. MRI of the wrist in early rheumatoid arthritis can be used to predict functional outcome at 6 years. Ann Rheum Dis 2004;63:555-61 